THURSDAY, FEBRUARY 22, I883

\section{PROFESSOR HENRY SMITH}

$\mathrm{O}^{\mathrm{N}}$ $\mathrm{N}$ Friday, the $9^{\text {th }}$ inst., we lost one of our most gifted men. By the death of Prof. Henry Smith there has dropped out from our roll-call a name which was already known among a wide circle of friends and admirers, but which would assuredly have been more widely known and more fully recognised if he had remained longer in our ranks.

Henry John Stephen Smith was born in Dublin, but when he was about two years old his family, at his father's deatb, removed to England. His precocity from the earliest age was remarkable; but what was perhaps still more remarkable, the talents which he thus showed did not, as is so often the case, fail him in after life. He was a fair haired child, and was known among his relations as the "white crow." When he was two years old it was understood that he could read; and on his third birthday it was agreed that he should be tried, on the condition that, in the case of failure, the white crow should be allowed to fly out of the window, which was set open for the purpose. It is needless to add that there was no occasion for flight. At the age of four he was found one day lying flat on the floor, with his face raised slightly above his book (his sight being, even then, short) teaching himself Greek from an old-fashioned grammar full of antique contractions in the characters. His subsequent education was carried on until he was eleven by his mother, and then by tutors. For an account of the rapidity with which he galloped over the ground with one of them, we are indebted to an interesting letter in the Times of the 12 th inst. With a view to his education the family removed to Oxford in I840, whence he was transplanted to Rugby. He entered the school in August, I84I, the commencement of the last year of Dr. Arnold's Head Mastership, and was in the Boarding House of the late Rev. Henry Highton, who was himself an old Rugbeian, a pupil of Arnold, and CoExhibitioner from the school with the present Dean of Llandaff and the late Dean of Westminster, and had lately graduated at Oxford, taking a First Class in Classics and a Second in Mathematics. Henry Smith had been Highton's private pupil at Oxford, and was so well taught that when he entered Rugby he was (although only then fourteen) placed in the fifth form, which is the highest form but one below the sixth, and which, by the rules of the school, is the highest in which a new boy can be placed. He was distinguished at Rugby for his unvarying gentleness of character, and was a favourite alike with masters and boys. An old schoolfellow writes of him thus: "I was a young boy in the house, and remember being struck with his great gentleness and amiability. It did me good at once, and I felt it, as I believe, to my lasting benefit." $\mathrm{He}$ was always much attached to his old friend and tutor, Highton; and ever since the latter's death, in December, 1874 , no one has shown more kindness to his widow and children than Henry Smith. At Rugby he progressed as rapidly as elsewhere, and was kept back from entering the sixth form under Arnold, only on account of his age. He was the first boy promoted to that form under Dr. Tait, Dr. Arnold's successor. Vol. XxVII.-No. 695
Nothing in fact seemed capable of stopping his intellectual career. The death of his only brother and his consequent withdrawal from school, which would have thrown most boys entirely out of gear, did not interfere with his gaining, at the age of eighteen the scholarship at Balliol. A severe illness delayed his residence at college, but neither the malady itself, nor absence from England, nor severance from books prevented him in 1848 , winning the blue ribbon in classics among Oxford undergraduates-the Ireland Scholarship. In I 850 he took his degree, obtaining an old-fashioned "Double First," namely, in classics and mathematics. The next year he gained the Senior Mathematical Scholarship; and if in this he had but few competitors, it was because his strength and powers were already known. After such a University career, almost unparalleled in the annals of Oxford, it seems but a natural consequence that he should be elected, as was the case, to a Fellowship at his College. In I86I he was elected successor to the late Baden Powell in the Savilian Professorship of Geometry, which chair he retained until his death. With a view to relieving him from the labour and duties of College tuition, which he had faithfully discharged for five-andtwenty years, Corpus Christi College offered him a Fellowship free from such duties. Notwithstanding his regret at leaving (although, as it subsequently proved, temporarily) his old college, he decided, having reference to the growing calls upon his time, to accept the offer. But Balliol, unwilling to lose all connection with its distinguished alumnus, afterwards bestowed upon him an honorary Fellowship, and, under the recent Statutes, a full Fellowship without emolument.

The malady under which he ultimately sank may be considered hereditary, for his father died from the same cause, and the son showed symptoms of it even at an early age. It is idle now to speculate whether a quieter or less exhausting life would have prolonged his years. There is some truth in the idea that a man can first and last perform a certain amount of work and no more. On this supposition it may be even a gain to the individual to have performed his task in the minimum of time, while those who remain must rest thankful at having lived in his day, and having retained him amongst us as long as was the case.

The testimony of his friends to his ability and other qualities is from all quarters abundant. Prof. Huxley writes : "Henry Smith impressed me as one of the ablest men I ever met with; and the effect of his great powers was almost whimsically exaggerated by his extreme gentleness of manner, and the playful way in which his epigrams were scattered about. They were so bright and sharp that they transfixed their object without hurting him. I think that he would have been one of the greatest men of our time, if he had added to his wonderfully keen intellect and strangely varied and extensive knowledge the power of caring very strongly about the attainment of any object." Although the present writer is not likely to differ much from Prof. Huxley in his estimate of the man, he would still suggest that Henry Smith's care for the attainment of an object was measured rather by his estimate of its ultimate value than by its present advantage. For those who knew him best were most fully aware of the effort which it cost him to postpone (as he 
often did, with apparent readiness) his beloved mathematics to other claims. Another friend says: "He was a man of rare powers, and as guileless as he was richly gifted."

Of some men it is said that they were never young, of others that they became old while their contemporaries were still lads; and it has been stated as a general law, in scientific thought at least, that the best and most original ideas have always been conceived before the age of thirty. But whatever may be the case in this respect with the generality of men, Henry Smith was as young and vigorous in intellect at the age of fifty-six, the limit to which he attained, as he was when he gained the first of his many University honours. It was his freshness of mind, his vivid appreciation and intelligent enjoyment of everything going on, not only in science, but also in life, whether social or political, which made us forget that his years, like ours, were passing away, and that the number of them was finite. It was his genial presence, his sympathetic attention, his ready counsel, his sound judgment, his happy mode of dealing with both men and things, which make us already feel a loss which we cannot as yet fully appreciate, but which we can never hope again completely to replace.

Of many Greek towns it is related that each has claimed for itself the honour of having been the birthplace of Homer; in like manner, many branches of knowledge, and avocations of life, might claim to have been the favourite pursuit of Henry Smith. But however proficient, or even prominent he may have been in other subjects, it was in mathematics that he mainly showed the originality of his genius, and that he has left any permanent record of work of the highest kind.

Among the great works which it was long hoped that he would have accomplished was his treatise on the Theory of Numbers. This subject, which during the present generation has been so marvellously generalised as to undergo a complete transfiguration since it was presented to us in the work of Barlow and in the ordinary educational books on Algebra, formed for many years a serious study on the part of Prof. Henry Smith. The papers in which the researches of mathematicians on this subject are recorded are scattered through the pages of various periodicals, so that it is not easy to realise the steps which each writer has contributed to the general progress, nor to assign to each his relative position. But this is not all, nor even the worst; it has been a prevailing custom, too prevalent we think, among mathematicians of late years, to publish results alone, without proof of their statements, and even without indication of the train of argument which led them to their conclusions. This naturally entails on the part of the reader either a strong act of faith or a difficult and, as we hold, unnecessary effort. It need hardly be added that in endeavouring to digest and present to his readers what had been done by others in his subject, Henry Smith adopted the latter course ; and, with a sagacity in which few could have rivalled him, he assimilated all these fragments, and utilising the valuable among these disjecta membra, and rejecting the wortbless, he brought them into harmony, and was in a fair way to produce from them a structure intelligible in itself, and capable of forming a groundwork for further developments. But while our author was dis- cussing what had been already done, the very materials upon which he was engaged were growing apace, and his self-imposed task accumulated upon him. Of unfinished work, or of "ragged ends" as he used to call them, he was as nearly intolerant as he could be of anything; and it is not clearly known whether he ever made up his mind to complete what he had undertaken up to a certain date or not. In any case what he had alreajy long ago achieved in this matter must have been a gigantic work; and it remains only to hope that his manuscripts have been left in such a state that others may be able to wield the weapons which he had forged.

The results of his preliminary studies were given in his six invaluable Reports on the Theory of Numbers, published in the volumes of the British Association for 1859 and following nearly consecutive years; and these alone are sufficient to show the extent of his reading and the firm grasp which he had of the subject. The following extracts from the first and third of these Reports indicate both the wide range of the theory and the magnitude of the portion which still remains to be achieved :-

"There are two principal branches of the higher arithmetic: the Theory of Congruences and the Theory of Homogeneous Forms. In a general point of view these two theories are hardly more distinct from one another than are in algebra the two theories to which they respectively correspond, namely, the Theory of Equations and that of Homogeneous Functions; and it might, at first sight, appear as if there were not sufficient foundation for the distinction. But, in the present state of our knowledge, the methods applicable to, and the researches suggested by, these two problems, are sufficiently distinct to justify their separation from one another."

"It is hardly necessary to state that what has been done towards obtaining a complete solution of the Representation of Numbers by Forms, and the Transformation of Forms, is but very little compared with what remains to be done. Our knowledge of the algebra of homogeneous forms (notwithstanding the accessions which it has received in recent times $[186 \mathrm{I}]$ ), is far too incomplete to enable us even to attempt a solution of them co-extensive with their general expression. And even if our algebra were so far advanced as to supply us with that knowledge of the invariants and other concomitants of homogeneous forms, which is an essential preliminary to an investigation of their arithmetical properties, it is probable that this arithmetical investigation itself would present equal difficulties. The science, therefore, has as yet had to confine itself to the study of particular sorts of forms; and of these (excepting linear forms, and forms containing only one indeterminate) the only sort of which our knowledge can be said to have any approach to completeness are the binary quadratic forms, the first in order of simplicity, as they doubtless are in importance."

Prof. Smith's sphere of utility was, as indeed is pretty well known, not confined to his University, nor to science as such, but extended, among other directions, even to departments of the State. Passing over the Royal Commissions on Scientific Education and on the University of Oxford, of both of which he was a leading member, mention must not be omitted of the Meteorological Council of which he was chairman. That body, nominated by the Royal Society, but appointed by the Government, 
holds a position intermediate between a public department and an independent institution. While on the one hand this intermediate position presents some advantages, at all events in the present stage of the subject as a science, it undoubtedly, on the other, requires no inconsiderable tact and judgment in its management. For the yearly administration of a large sum of public money, for the management of a considerable staff at home, and of a variety of observers at out-stations in all parts of the country, and for communication with similar departments of State in foreign countries, science alone would not have sufficed. But at the same time few branches of natural knowledge stand more in need of a strong scientific guide to keep it from the crotchets of dabblers in the subject, or from relapsing into an indiscriminate accumulation of loose observations from which no valuable result can ever be derived. For this post the President and Council of the Royal Society unanimously nominated him, nor had they ever reason to regret the step which they then took.

The case of the Meteorological Council was, however, but one instance out of many in which his name came uppermost in the minds of men when they were looking for a leader, or a chairman, or a president. Whether as President of the Mathematical Society (1874-6), or of the Mathematical and Physical Section of the British Association (1873), or as Chairman of Committees too many to enumerate, he always succeeded in commanding the respect of those with whom he was associated, and in carrying through the business to a satisfactory issue.

In one matter only did he fail of success; but in that case the failure was not really his, but that of those who should have given him support. The case was that of his candidature for the representation of the University of Oxford, when, in 1878 , Lord Cranbrook received his peerage. Instances of the candidature of leading University men, both in Oxford and in Cambridge, have not been unknown, from the time of the late Sir John Lefevre to that of Prof. Stuart; but all have terminated in the same result, namely, the total defeat of every man of University distinction, whatever other qualifications he may have for the office. With these instances we may compare, not without interest and instruction, the choice which has been made by the University of London on the only two occasions on which a vacancy has yet occurred.

It was sometimes thought that his mind became diverted from mathematics by his many other distracting avocations; there are, however, reasons for doubting this. It is true that he did not pour out the amount of mathematical papers of which he was certainly capable; but those which he did publish showed that he cared little to add fringe-work to the borders of our knowledge, and that he reserved himself for questions of real importance. We remember his alluding to the subject of one of his later papers contributed to the Mathematical Society, on Modular Equations, as relating to "a point on which people had puzzled themselves for a long time," and the following passages from his address to the London Mathematical Society were certainly not penned by a president for whom that subject had lost its charm. "Of all branches of mathematical inquiry, this is the most remote from practical applications; and yet, more perhaps than any other, it has kindled an extraordinary enthusiasm in the minds of some of the greatest mathematicians." Then he quotes Gauss as having held Mathematics to be the Queen of the Sciences, and Arithmetic to be the Queen of Mathematics. I cio not know that the great achievements of such men as Tchébychef and Riemann can fairly be cited to encourage less highly gifted investigators; but at least they may serve to show two things-first, that nature has placed no insuperable barrier against the further advance of mathematical science in this direction; and secondly, that the boundaries of our present knowledge lie so close at hand that the inquirer has no very long journey to take before he finds himself in the unknown land. It is this peculiarity, perhaps, which gives such perpetual fresbness to the higher arithmetic. It is one of the oldest branches perhaps the very oldest branch, of human knowledge; and yet some of its most abstruse secrets lie close to its tritest truths. I do not know that a more striking example of this could be found than that which is furnished by the theorem of M. Tchébychef. To underderstand his demonstration requires only such algebra and mathematics as are at the command of many a schoolboy; and the method itself might have been invented by a schoolboy, if there were again a schoolboy with such an early maturity of genius as characterised Pascal, Gauss, or Evariste Galois."

The following is another instance of the interest which he retained in mathematics to the very last. In the address above quoted he alluded to a problem, at that time still unsolved, in the following terms :- "It was first shown by $M$. Liouville that irrational quantities exist which cannot be roots of any equation whatever, having integral coefficients. We may perhaps be allowed to designate by the terms arithmetical and transcendental the two classes of irrational quantities which M. Liouville has taught us to distinguish; and it becomes a problem of great interest to decide to which of these two classes we are to assign the irrational numbers, such as $\epsilon$ and $\pi$, which have acquired a fundamental importance in analysis. To Lambert, the eminent Berlin mathematician of Jast century, the first great step in this direction is due. $\mathrm{He}$ showed that neither $\pi$ nor $\pi^{2}$ is rational; with regard to $\epsilon$ he was even more successful, for he was able to prove that no power of $\epsilon$, of which the exponent is rational, can itself be rational. There (with one slight exception) the question remained for more than a century; and it was reserved for M. Hermite, in the year 1873 , to complete, by a singularly profound and beautiful analysis, the exponential theorem of Lambert, and to prove that the base of the Napierian logarithms is a transcendental irrational. But, in a letter to M. Borchardt, M. Hermite declines to enter on a similar research with regard to the number $\pi$. "Je ne me hasarderai point,' he says, 'à la recherche d'une démonstration de la transcendence du nombre $\pi$. Que d'autres tentent l'entreprise; nul ne sera plus heureux que moi de leur succès; mais croyez m'en, mon cher ami, il ne laissera pas que de leur en coûter quelques efforts.' It is a little mortifying to the pride which mathematicians naturally feel in the advance of their science to find that no progress should have been made for a hundred years and more toward answering the last question, which still 
remains unanswered, with regard to the rectification of the circle."

Last year, Lindemann, starting from Hermite's researches, succeeded in supplying the proof required with reference to the number $\pi$. And while speaking of this achievement with the satisfaction which his generous nature prompted, Henry Smith added that it was a problem on which he had long fixed his eye with a view to attacking it seriously so soon as he had leisure for the undertaking.

He was doubtless then looking forward to some University vacation; for vacation time formed the period for his original investigations, while term time was devoted to current work and to society, which he himself so keenly enjoyed, and in which he was always an honoured and a welcome guest.

It has been much the fashion of late years to raise memorials to the departed; and in some cases it may be doubted whether a wise discrimination has been exercised in the matter. No one, however, who has any interest in science, would doubt for a moment that the memory of Henry Smith was in the highest degree deserving of perpetuation. But in our opinion the best and only suitable memorial of him will be the publication of his works, in the fullest and most complete form of which they are now capable. And it is sincerely to be hoped that his MSS. may be placed in the hands of a mathematician who may prefix to them an introduction as worthy of these works as was Prof. Smith's introduction to the remains of Clifford.

During his last few years he lived, as Keeper of the University Museum, at the house adjoining the main building, previously occupied by his predecessor, John Phillips. His companion was his sister, whose useful and sympathetic life worthily supplemented his own. It is to be hoped when the wave of sorrow which is now passing over her has in some degree subsided, and when time has brought an alleviation which may now seem impossible, that she may derive satisfaction, although it be a melancholy one, in having learnt through the event how much her brother was appreciated and beloved by many, and by some even unknown, friends.

\section{W. SPOTTISWOODE}

\section{PUBLIC ELECTRIC LIGHTING}

$\mathrm{M}$ $\mathrm{UCH}$ attention is being given at the present moment to the operation of the Electric Lighting Act: passed during the last session of Parliament. Under the terms of that Act, licenses and provisional orders will be granted to local authorities, companies, and private individuals to supply electricity for the purpose of electric lighting over definite areas. A large number of applications for licenses and provisional orders have already been submitted to the Board of Trade, in a few instances by local authorities, but in the majority of cases by joint-stock companies formed for working one or other of the different systems for electric lighting. A number of the "Provisional Orders" now being promoted lie before us, the majority of them being drawn in almost identical terms. A perusal of these documents cannot fail to impress the reader, firstly, with the great complexity of the question, secondly, with the extreme difficulty of striking a fair balance between vested interests and public convenience, thirdly, with the great amount of knowledge and skill displayed in the drafting of these provisional orders. It is an open secret that not only the main outlines but also most of the details of these orders are from the hand of Mr. J. Fletcher Moulton, F.R.S., whom we must congratulate upon the success with which he has applied himself to the task of preparing them. Now that Parliament is once more in session we shall probably hear of further legislative proposals; but if all provisional orders are as well and as wisely drawn as the majority of those before us appear to be, there can be little doubt that the necessity for separate further legislation and for the promotion of private bills for electric lighting will be removed.

As to the provisional orders themselves it would be impossible within reasonable limits to deal with a tithe of the important topics which are therein set forth. Many of the provisions are naturally directed toward questions of municipal rights and parochial law. Leaving aside all these matters we come to the more scientific points. Four separate systems of distribution are recognised in the provisional orders. These are $(a)$ "direct" system, more familiar under the name of distribution in parallel arc, with "distributing mains" throwing off "service lines" for individual consumers; (b) "storage" system, with service lines in parallel arc from storage batteries charged in series intermittently from a generating station; (c) either of the above with "earth " returns ; $(d)$ "series" system, supplying customers in one undivided circuit. We may remark in passing that it appears to us that the use of "earth" for return should be in every case forbidden. If currents of the intensity employed for electric lighting are sent through earth in our crowded cities we shall have constant derangements of telegraphs, telephones, electric bells, in fact of all electric appliances which work by feeble currents and use earth returns. Moreover, as "earth" in practice means usually the employment of existing gas-pipes or water-pipes as returns the proposal to utilise "earth" for electric light returns, is doubly to be deprecated. Amongst other limitations set forth in the provisional orders are some which bind the "undertakers" to lay down their mains within two years, some which prescribe the hours during which the supply of currents must be maintained, and some which limit the conditions of supply. Amongst the latter we observe in several of the orders before us that it is proposed that "the potential at corresponding points of the positive and negative distributing mains shall differ at each point by a constant difference, not being less than thirty volts, and not being more than four hundred volts." And that "such constant difference of potential" is to be termed "the standard pressure." It is to be hoped that the Board of Trade will be much more precise in its limitations. Thirty volts is so low a "pressure" as to be practically out of the question except with a gigantic outlay in copper conductors, whilst four hundred volts is equally inadmissible on account of the danger to person. No less an authority than Sir W. Thomson has said that nothing above two hundred volts should ever be admitted into a dwelling-house. The provision that "the standard pressure may be different for different points of the said mains, and for different hours during the period of supply" 